\title{
The Finite Element Analysis and Geometry Improvements of Some Structural Parts of a Diesel Forklift Truck
}

\author{
Ömer Yavuz Bozkurt ${ }^{1}$, İhsan Cihan Dai ${ }^{2}$, Özkan Özbek ${ }^{1}$ \\ ${ }^{1}$ Mechanical Engineering Department, Gaziantep University, Gaziantep, Turkey \\ ${ }^{2}$ Sanko Machine, ARGE Department, Gaziantep, Turkey
}

\begin{tabular}{l} 
Article Info \\
\hline Article history: \\
Received May $30^{\text {th }}, 2017$ \\
Revised June $15^{\text {th }}, 2017$ \\
Accepted June $17^{\text {th }}, 2017$ \\
\hline
\end{tabular}

Keyword:

Finite element analysis

Forklift

Msc SimXpert Nastran

\begin{abstract}
In this work, static analyses of structural parts of a diesel forklift were performed using Finite Element Method and possible modifications based on the original geometry of parts were utilized with respect to stress distributions at critical region to improve reliability of the forklift design. The analyses were carried out according to standard regulations related with the examined parts. The structural parts of forklift such as chassis and head guard were analysed under compulsion loading conditions. The improvements in relevant parts were demonstrated by the comparison of stress values of original and modified geometries. The finite element analyses were carried out using MSC SimXpert Nastran Finite Element software package.
\end{abstract}

\section{Corresponding Author:}

Özkan Özbek,

Mechanical Engineerin Department,

Gaziantep University,

27310, Gaziantep, Turkey.

Email: ozkanozbek@gantep.edu.tr

\section{Introduction}

Forklift is a relatively small industrial vehicle used to carry industrial goods in a short distances by two power-operated forks at the front. It is also called as a lift truck, a fork truck, or a forklift truck. A forklift can be used in numerous places such as; warehouses, factories, farms, shipping yards, construction sites, supermarkets, and much more. Several different forklift models are found in literature. They can be categorized based on their design, i.e. capabilities, size and methods of operation.

The tests or testing steps are one of the most important and necessary part of a design procedure. Several tests must be performed to develop a new product. Due to requirement of long time durations and production of a prototype, destructive and non-destructive physical tests are generally expensive and adversely affect the product's time to enter the market. In today's world, computer simulations are carried out to improve the efficiency of design procedures in terms of cost and time by reducing or eliminating the need of physical tests. Finite element method (FEM) is the most widely used numerical analysis method in the computer simulations. The FEM does not require a physical prototype production and it can be used to analyse any parts/components of the whole system under certain operating conditions. Also, it permits improvements in the reliability of product by changing the design according to the results of analysis.

In the literature, there are several articles on the open literature associated with the finite element analysis of forklifts. Bhagat et al. [1] developed the CAD model of a translation carriage for reach truck and performed the static analyse of it under various loading and boundary conditions using finite element analysis in ANSYS environment. Doçi et al. [2] examined the structural behaviours of forklift under dynamic loadings and specified the parameters that affect the dynamic behaviours of forklift. Meshram [3] developed 3D models for the forklift mast with a change in geometry to perform of structural analysis using finite element method. 
Also, in terms of stress distribution, the performance of structural steel and gray cast iron were compared using the same boundary conditions. Rane et al. [4] carried out topology optimization technique for the design of forklift chassis to reduce the weight without changing the working conditions of forklift. Cline [5] conducted fatigue analysis of forklift forks applying loads at two different positions; centred and offset. Miralbes et al. [6] designed the crane gibs and pallet box lock for a forklift truck using finite element analysis. The boundary conditions were provided according to the forklift truck regulations. Stoychev and Chankov [7] proposed a dynamic model to investigate the stresses for the lifting installation of a forklift truck. Todorov et al. [8] constructed a virtual design of a forklift transmission module and improved it by executing thermal and structural analysis with finite element method.

In this paper, some of the mechanical construction parts of a diesel forklift with three ton capacity is analysed using finite element method and geometry changes on 3D solid model of these forklift construction parts are applied to improve the reliability of design by reducing stress values at critical sections.

\section{Geometrical View and Technical Parameters}

General view of the diesel forklift marked with major parts is shown in Fig. 1 and some of its technical parameters such as carrying capacity, dimensions, engine power and driving speed are presented in Table 1.
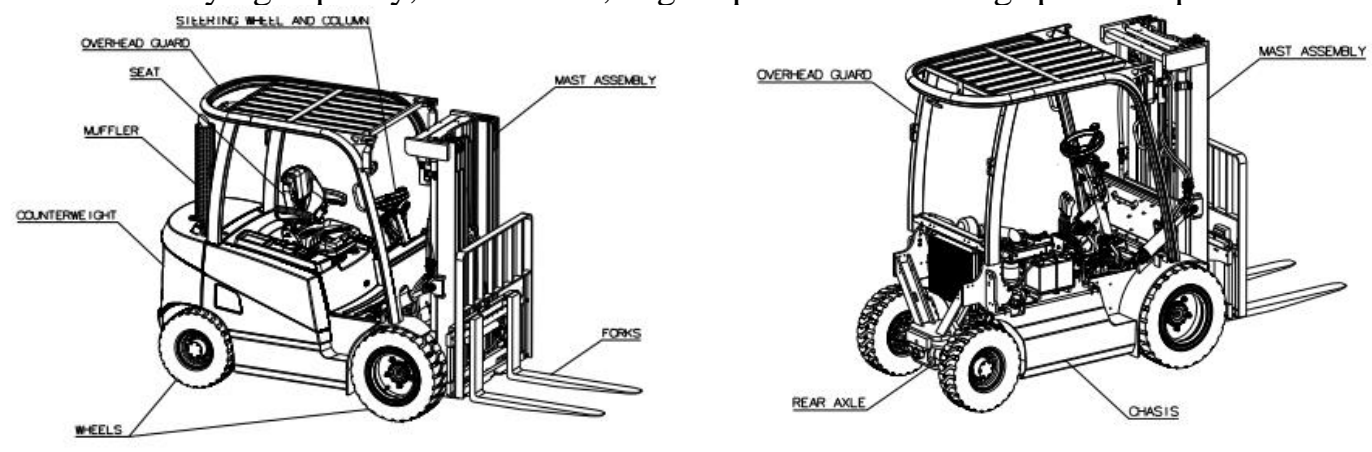

Figure 1. General view of a diesel forklift.

Table 1. Diesel forklift technical parameters

\begin{tabular}{ll}
\hline Power unit & Diesel \\
Carrying capacity/load & $3000 \mathrm{~kg}$ \\
Load centre & $500 \mathrm{~mm}$ \\
Wheel base & $1720 \mathrm{~mm}$ \\
Weight & $4500 \mathrm{~kg}$ \\
Tilt angle, mast/fork carriage forwards & $6^{\circ}$ \\
Tilt angle, mast/fork carriage backwards & $10^{\circ}$ \\
Lift height & $3230 \mathrm{~mm}$ \\
Overall length & $3757 \mathrm{~mm}$ \\
Fork thickness & $45 \mathrm{~mm}$ \\
Fork width & $100 \mathrm{~mm}$ \\
Fork length & $1000 \mathrm{~mm}$ \\
Fork carriage DIN 15173 & $2 \mathrm{~A}$ \\
Turning radius & $2400 \mathrm{~mm}$ \\
Driving speed with load & $18.2 \mathrm{~km} / \mathrm{h}$ \\
Driving speed without load & $19.5 \mathrm{~km} / \mathrm{h}$ \\
Engine Power & $35,5 \mathrm{~kW} \quad 2400$ \\
& $\mathrm{rpm}$ \\
\hline
\end{tabular}

\section{Analysis of Chassis}

The chassis is the main supporting structure of the forklift truck which all other components are attached. The 3D solid model for the chassis of forklift truck is shown in Fig. 2. The calculations of external loads are carried out using static loading, rigid connection member and linear-elastic material behaviour assumptions. 


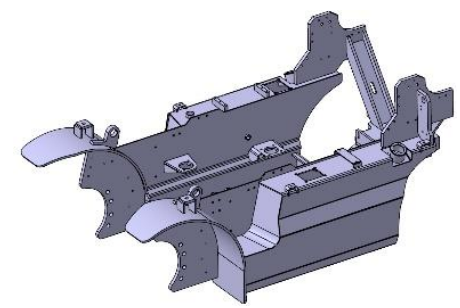

Figure 2. The 3D solid model of forklift chassis.

The maximum lifting capacity of forklift truck were analysed as $3000 \mathrm{~kg}$. According to the ISO 3691-1:2011 standard, the structural components of the truck and its attachments shall carry the static load of $1.33 \times 3000$ $\mathrm{kg}$. It is the rated capacity at standard lift height and standard load centre distance with respect to the information on the capacity plate.

The various loads acting on the chassis are shown in Fig. 3. The forces of tilt cylinders $\left(\mathrm{F}_{1}\right)$, total weight of cabin with seat, bonnet and operator $\left(\mathrm{F}_{2}\right)$, total weight of counterweight and muffler $\left(\mathrm{F}_{3}\right)$, weight of radiator $\left(\mathrm{F}_{4}\right)$, total weight of rear axle with wheels $\left(\mathrm{F}_{5}\right)$, and total weight of engine with transmission $\left(\mathrm{F}_{6}\right)$ are calculated as $93.227 \mathrm{kN}, 2.943 \mathrm{kN}, 17.462 \mathrm{kN}, 0.294 \mathrm{kN}, 1.589 \mathrm{kN}$ and $7.700 \mathrm{kN}$, respectively.
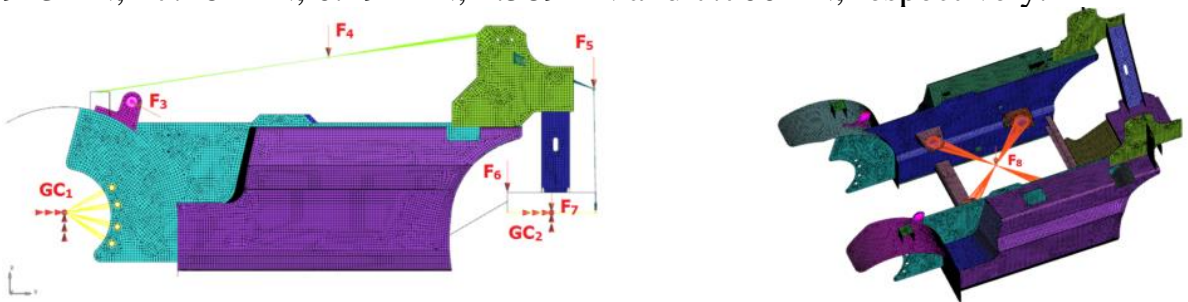

Figure 3. Loads acting on chassis.

The forces of tilt cylinders were examined using loading process of mast assembly at standard lift height under overload condition. The free body diagram of mast assembly is shown in Fig. 4. The mass of mast assembly is $1000 \mathrm{~kg}$. The $\mathrm{W}_{1}$ and $\mathrm{W}_{2}$ are the weights of pay load and mast assembly, respectively, and are calculated as $\mathrm{W}_{1}=39.142 \mathrm{kN}, \mathrm{W}_{2}=9.81 \mathrm{kN}$.
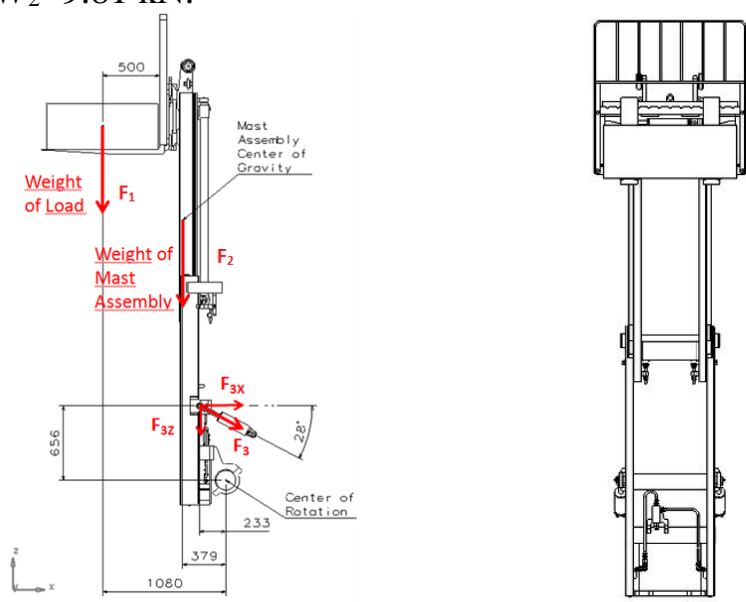

Figure 4. Free body diagram of mast assembly at standard lift height under overload condition.

The solid model, shown in Fig. 2, is meshed with 57289 elements in SimXpert Structure Analysis program. The finite element model of chassis is shown in Fig. 5. The chassis is made of St52-3 and the mechanical properties of St52-3 are given in Table 2.

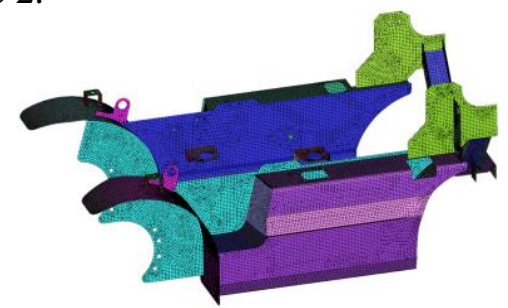

Figure 5. Finite element model of chassis. 
Table 2. The mechanical properties of St52-3

\begin{tabular}{lc}
\hline Material & St52-3 \\
\hline Yield Stress (MPa) & 355 \\
Ultimate Stress (MPa) & 530 \\
Poisson's Ratio & 0.3 \\
Young's Modulus (GPa) & 210 \\
\hline
\end{tabular}

The analysis of chassis is carried out in case of overload and standard lifting height, and the results are shown in Fig. 6. It is shown that the maximum von Mises stress is calculated as $257 \mathrm{MPa}$ at the connection bracket of tilt cylinders. The resulting stress is below the yield stress value of St52-3 material. So, there is no plastic deformation on this bracket. However, a stress concentration is shown and a design revision in geometry of bracket can be done to reduce stress values.

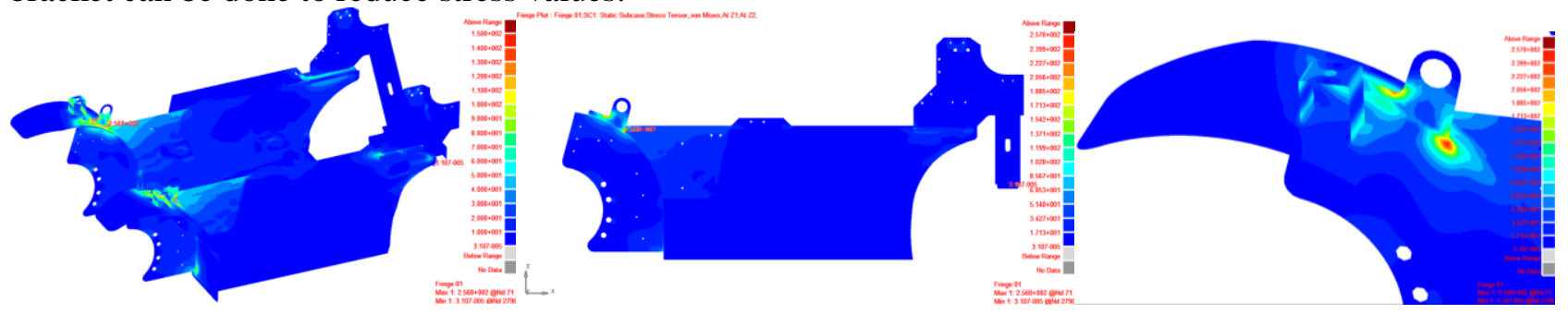

Figure 6. The FEA results of chassis. (a) Isometric view of chassis fem result; (b) Side view of chassis fem result; (c) Maximum Von Mises Stress in Tilt Cylinder Connection Bracket.

The front and rear tips of connection bracket show $232 \mathrm{MPa}$ and $257 \mathrm{MPa}$ for the magnitude of von Mises stress. These tip points are marked as A and B, respectively. Two new geometry is designed to improve reliability of connection bracket by reducing stress values. Finite element analysis of chassis have been performed for the new connection bracket designs and the results in terms of von Mises stress distribution are shown in Fig. 7. The first design revision in geometry made possible to reduce maximum von Mises stress to $214 \mathrm{MPa}$ from $257 \mathrm{MPa}$ and second one was reduced to $136 \mathrm{MPa}$. The von Mises stress comparisons of original and revised geometries of connection bracket is given in Table 3. As seen in Table 3, the factor of safety with respect to connection bracket design was increased from 1.38 to 2.08
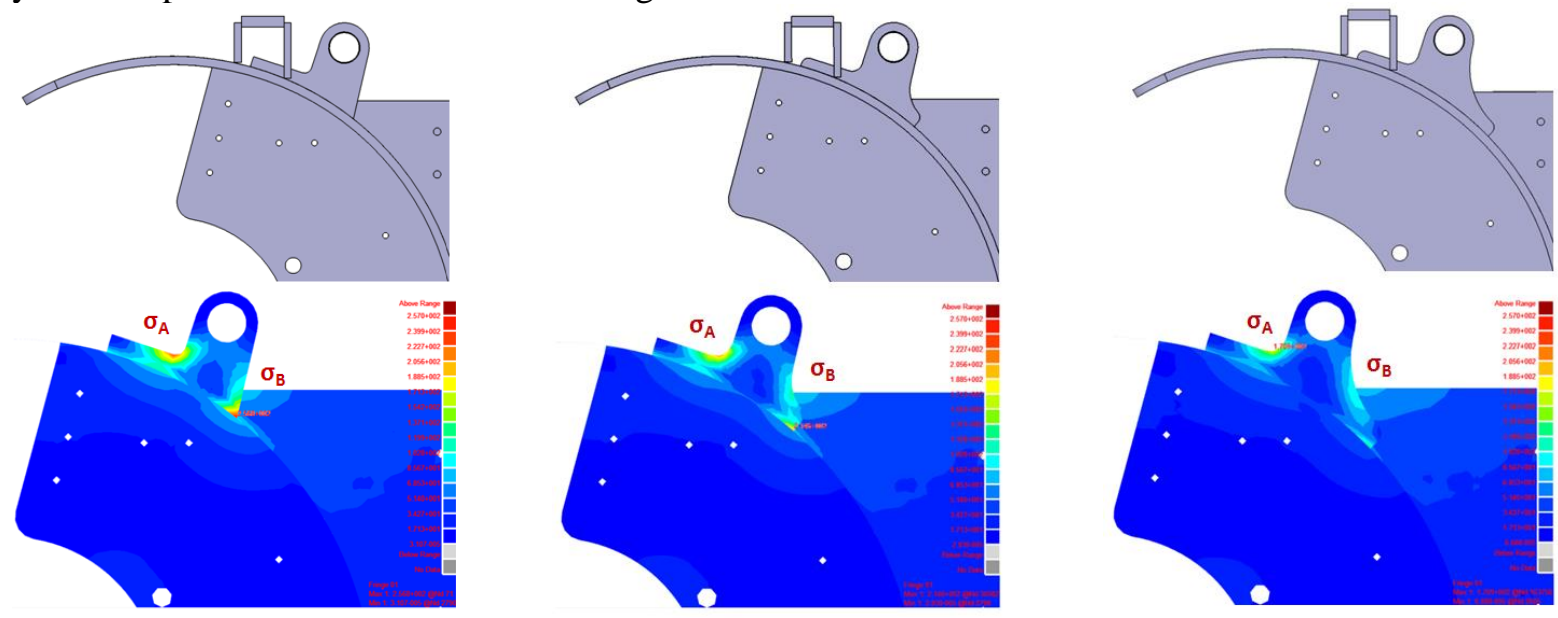

Figure 7. a) The original connection bracket, b) First revision of connection bracket, c) Second revision of connection bracket.

Table 3. Comparison of von misses stresses of tilt cylinder connection bracket

\begin{tabular}{lccc}
\hline Von Mises Stress & Original & Revision-1 & Revision-2 \\
\hline $\boldsymbol{\sigma}_{\mathbf{A}}(\mathbf{M P a})$ & 232 & 206 & 171 \\
$\boldsymbol{\sigma}_{\mathbf{B}}(\mathbf{M P a})$ & 257 & 214 & 136 \\
Factor of Safety & 1.38 & 1.66 & 2.08 \\
\hline
\end{tabular}




\section{Analysis of Head Guard}

The forklift trucks can be very dangerous. Serious or fatal injuries from forklift incidents, especially for rollovers, can be happened for the forklift operators. The forklift manufacturers have formal responsibility for designing forklifts with protective structures that guard forklift operators under certain conditions. In this section, ROPS (Roll-over protective structures) test of forklift truck was simulated using finite element analysis. The simulation was carried out in accordance to EN ISO 3471 standard. Solid model of head guard and seated operator are given in Fig. 8. The model of seated operator is prepared as described in EN ISO 3411 standard and it is positioned to the sit point.
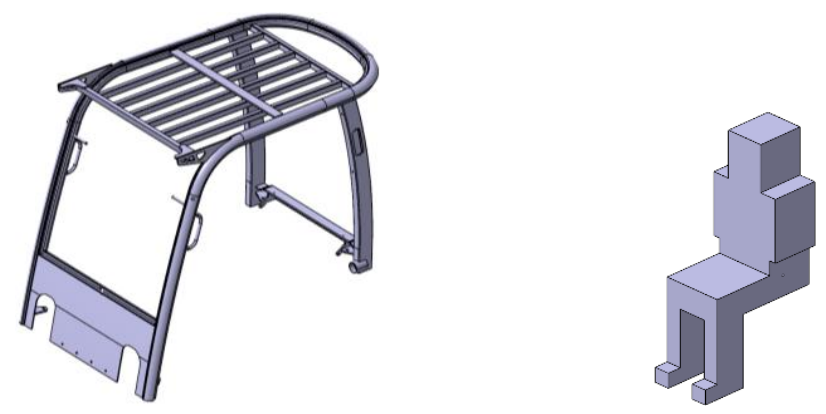

Figure 8. a) Forklift Head Guard Solid Model b) Seated Operator.

In the ROPS analysis, the material of head guard was identified as St52-3. The stress values can exceed the yield value according to ROPS analysis. Therefore, the ROPS analysis of head guard is solved as a nonlinear analysis. Stress-strain values of St52-3 material are shown in Fig. 9.

The applied load and energy of the load shall be met at least a certain level in the ROPS test. The stress values can be over the yield stress value to satisfy this requirement and due to this possibility ROPS analysis was performed as nonlinear analysis. The amount of required lateral, vertical and longitudinal loads which are formulated in relation to the weight of forklift are given in EN ISO 3471 standard. The weight of the forklift was presented in Table 1. According to EN ISO 3471 standard, forklift truck is classified in the wheeled earthmoving machine category, and the lateral load, lateral load energy, vertical load and longitudinal load are calculated as follows:

$$
\begin{aligned}
& \mathrm{F}_{\text {lateral }}=6 \times \mathrm{M}=6 \times 4500=27 \mathrm{kN} \\
& \mathrm{E}_{\text {lateral }}=12500 \times[(\mathrm{M} \div 10000)]^{1.25}=12500 \times[(4500 \div 10000)]^{1.25}=4.607 \mathrm{~kJ} \\
& \mathrm{~F}_{\text {vertical }}=19.6 \times \mathrm{M}=19.6 \times 4500=88.2 \mathrm{kN} \\
& \mathrm{F}_{\text {longitudinal }}=4.8 \times \mathrm{M}=4.8 \times 4500=21.6 \mathrm{kN}
\end{aligned}
$$

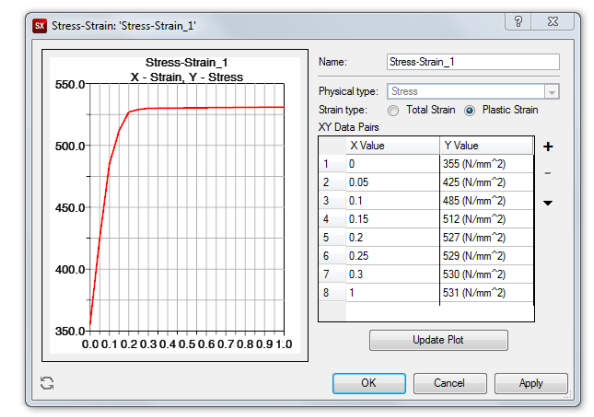

Figure 9. Stress-strain values of St 52-3 material.

The finite element model of head guard, shown in Fig. 10, has been formed from the solid model presented in Fig. 8. It has 22909 elements and in general consists of quadrilateral elements. The load distribution devices used for the load application was also modelled with solid mesh. 


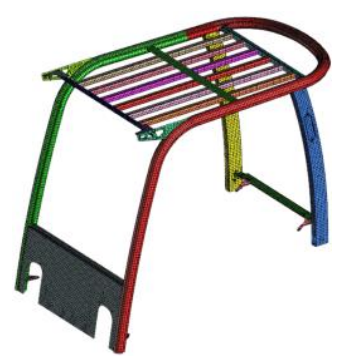

Figure 10. Finite Element Model of Head Guard.

The prescribed boundary conditions and applied loads on the head guard for the lateral, vertical and longitudinal loadings are shown in Fig. 11. The load distribution devices for the loading procedures are also shown in Fig. 11. The lateral force, $\mathrm{F}_{\text {lateral, }}$, vertical force, $\mathrm{F}_{\text {vertical, }}$, and longitudinal force, $\mathrm{F}_{\text {longitudinal, were }}$ calculated as $27 \mathrm{kN}, 88.2 \mathrm{kN}$ and $21.6 \mathrm{kN}$, respectively. $\mathrm{FC}_{1}, \mathrm{FC}_{2}, \mathrm{FC}_{3}, \mathrm{FC}_{4}, \mathrm{FC}_{5}, \mathrm{FC}_{6}, \mathrm{FC}_{7}, \mathrm{FC}_{8}, \mathrm{FC}_{9}, \mathrm{FC}_{10}$, $\mathrm{FC}_{11}$ and $\mathrm{FC}_{12}$ show that all degrees of freedom for connection parts of the head guard are restrained.
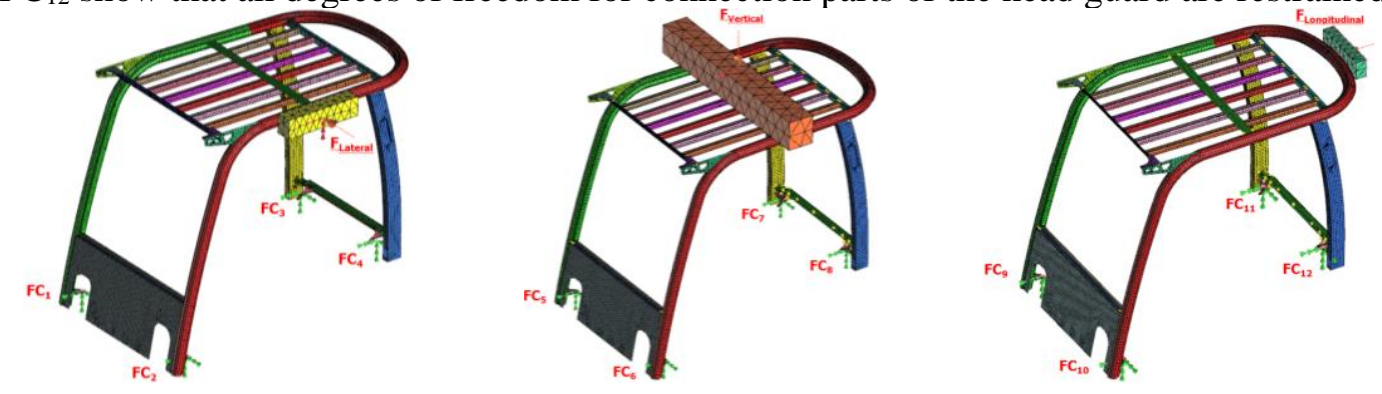

Figure 11. Loading Cases of Head Guard. (a) $\mathrm{F}_{\text {lateral }}$ force, $\mathrm{FC}_{1}, \mathrm{FC}_{2}, \mathrm{FC}_{3}$ and $\mathrm{FC}_{4}$ Fixed Constraints; (b) $\mathrm{F}_{\text {vertical }}$ force, $\mathrm{FC}_{5}, \mathrm{FC}_{6}, \mathrm{FC}_{7}$ and $\mathrm{FC}_{8}$ Fixed Constraints; (c) $\mathrm{F}_{\text {longitudinal }}$ force, $\mathrm{FC}_{9}, \mathrm{FC}_{10}, \mathrm{FC}_{11}$ and $\mathrm{FC}_{12}$ Fixed Constraints.

The lateral loading procedure was carried out using the load distribution device. At the end of the lateral loading, maximum stress value was measured as $411 \mathrm{MPa}$. Maximum deformation was measured as $87 \mathrm{~mm}$. During the loading, head guard didn't enter to the seated operator area, but it has a permanent deformation. FEM results of lateral loading are shown in Fig. 12 and load-displacement curve is given in Fig. 13.
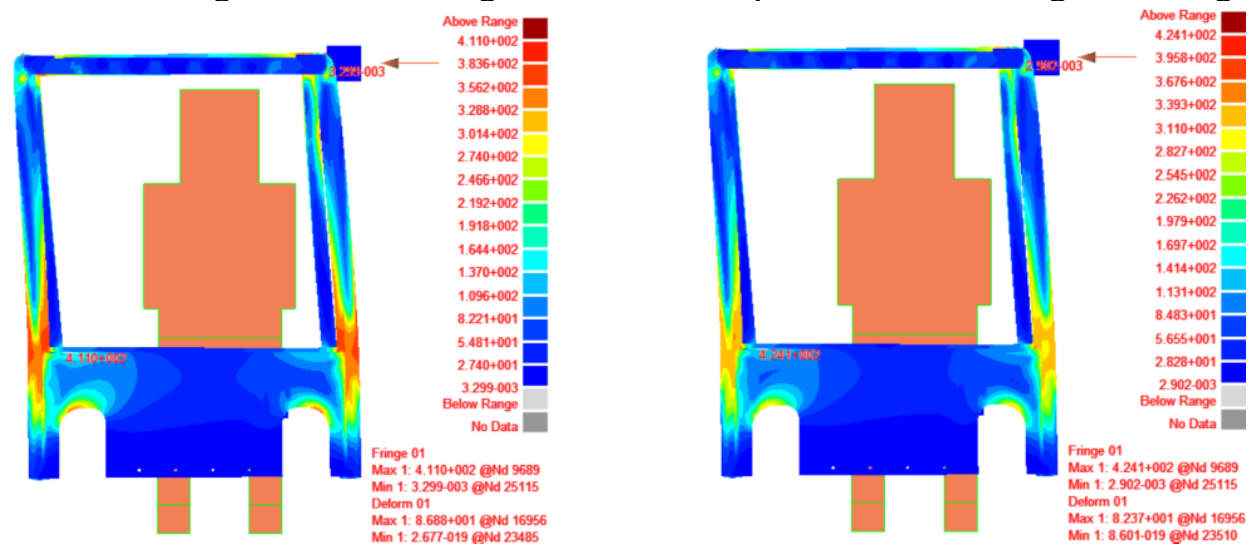

Figure 12. FEM results of Lateral Loading (a) Maximum Loading; (b) Load Removed.

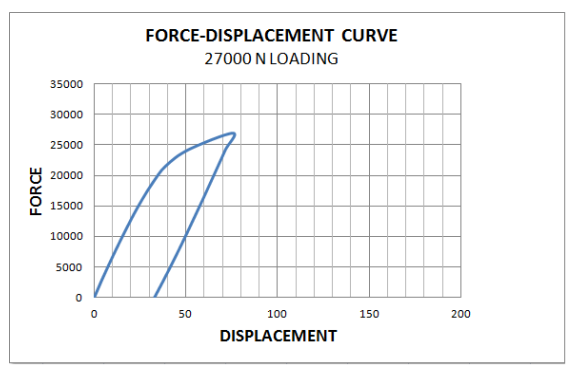

Figure 13. Force-Displacement curve under the application of $27 \mathrm{kN}$ load. 
During the loading period, the head guard structure was permanently deformed but not in the operator area defined according to the specified standards. With the $1373 \mathrm{~J}$ energy generated by applying load of $27 \mathrm{kN}$, the energy requirement of $4607 \mathrm{~J}$ defined in the ROPS standard was not met. For this reason, a load of $32 \mathrm{kN}$ was applied by increasing the amount of load to meet the energy requirement, and the energy requirement of the ROPS standard was met by the $4758 \mathrm{~J}$ energy output. The maximum tensile value obtained at $32 \mathrm{kN}$ loading was $481 \mathrm{MPa}$ and the maximum deformation value at force application point was determined as $189.5 \mathrm{~mm}$. The results of the finite element method obtained from lateral load of $32 \mathrm{kN}$ are shown in Fig. 14. The loaddisplacement curve graph is shown in Fig. 15. During the loading period, the head guard did not enter the operator area.
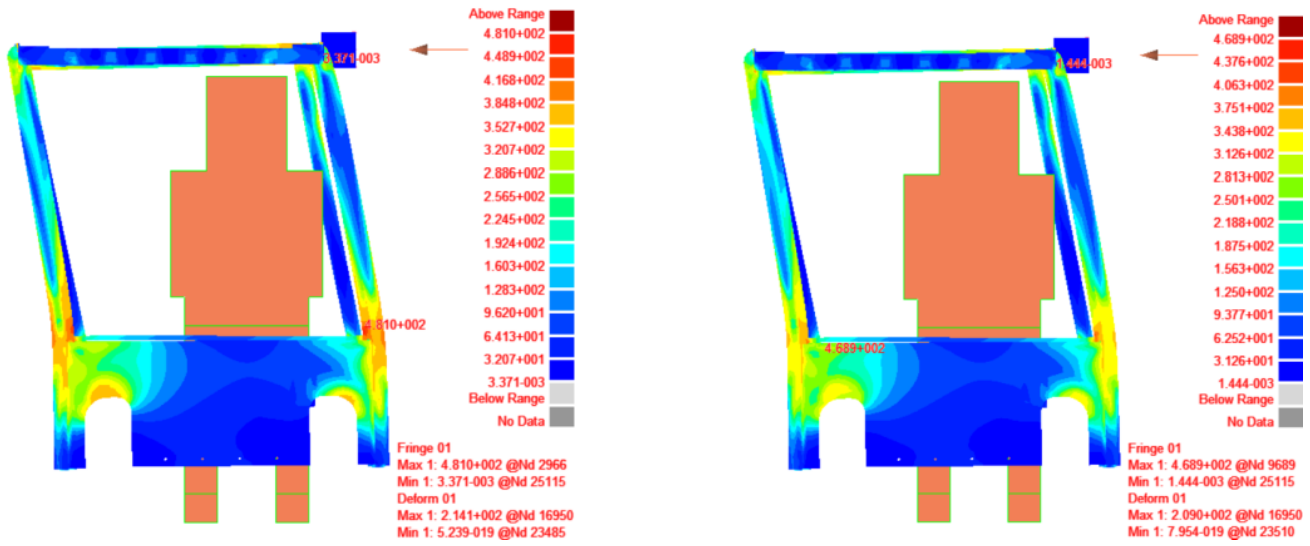

Figure 14. FEM results of Lateral Loading (a)Maximum Loading; (b) Load Removed.

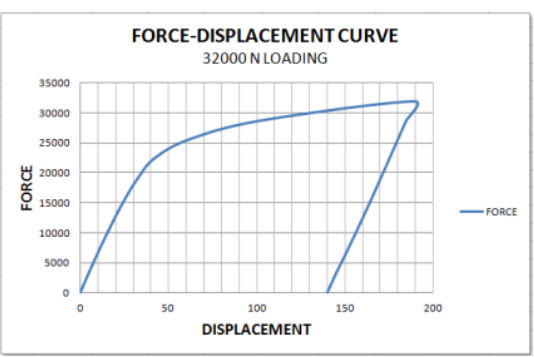

Figure 15. Force-Displacement curve under the application of $32 \mathrm{kN}$ load.

Vertical loading was carried out using the long load distribution device from the cabin. At the end of the vertical loading, maximum stress value was measured as $359 \mathrm{MPa}$. Maximum deformation was measured as $7.8 \mathrm{~mm}$. During the loading, head guard didn't enter to the seated operator area. Head guard has a permanent deformation, no cracks have occurred in the cabin. FEM results of vertical loading was shown in Fig. 16.
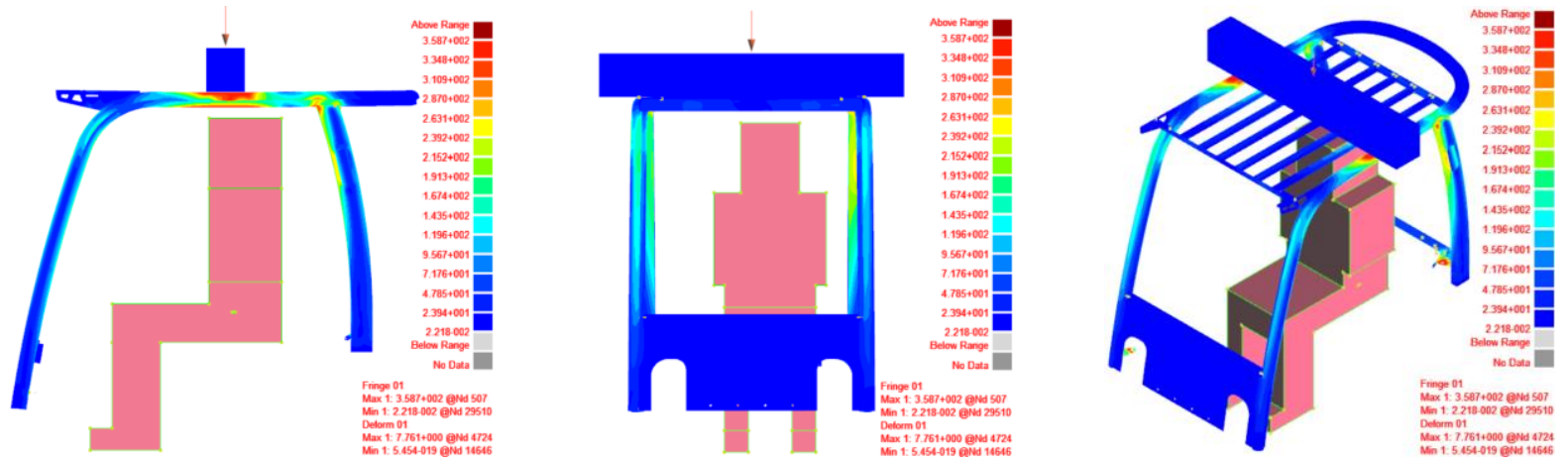

Figure 16. FEM results of Vertical Loading (a) Isometric view of fem result; (b) Front view of fem result; (c) Side view of fem result.

Longitudinal loading was carried out using the load distribution device. At the end of the longitudinal loading, maximum stress value was measured as $354 \mathrm{MPa}$. Maximum deformation was measured as $17 \mathrm{~mm}$. During 
the loading, head guard didn't enter to the seated operator area. Head guard has no permanent deformation, no cracks have occurred in the cabin. FEM results of longitudinal loading was shown in Fig. 17.
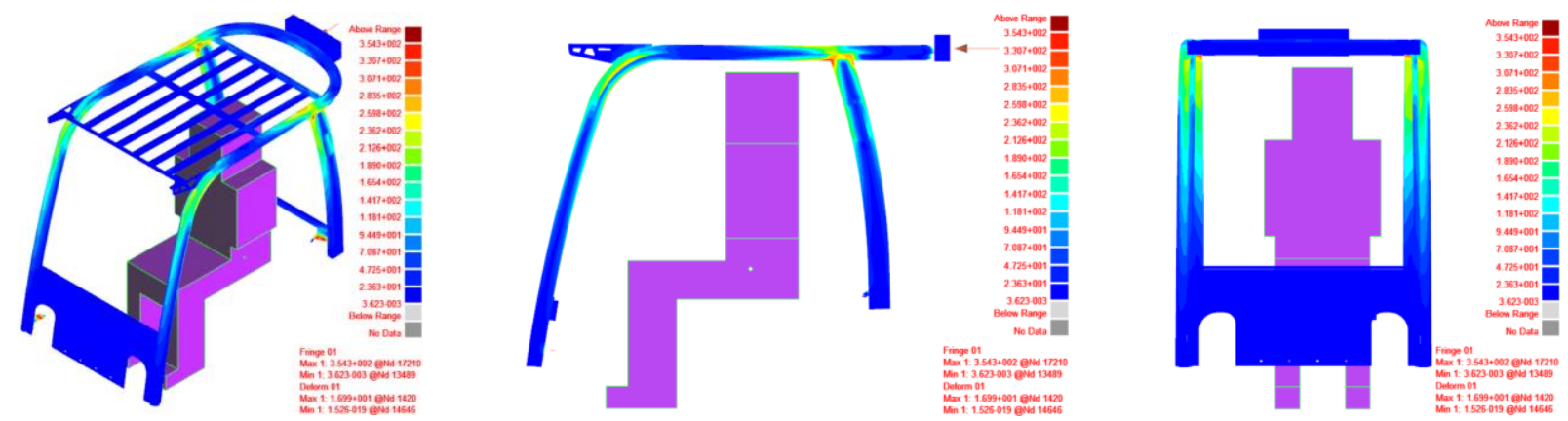

Figure 17. FEM results of Longitudinal Loading (a) Isometric view of fem result; (b) Front view of fem result; (c) Side view of fem result.

\section{Conclusions}

In this study, static analysis of some structural parts such as chassis, head guard of a diesel forklift truck was performed by using finite element method. Critical regions with high stress values were determined according to the analysis results and design geometries were changed to reduce stresses in there. The analysis results that belong the original models and modified models were compared. The analysis of modified models with new geometries showed that the reliability of the design was improved by lower stresses. For operator safety, the maximum stress and deformation values that can occur in overload and overturn situations are determined by finite element analysis. The maximum lateral, vertical and longitudinal force values that can be applied to the head guard and their application forms are determined according to EN ISO 3471 standard. According to the results of deformation under these loads; the head guard was subjected to permanent deformation, but this deformation was observed to have no adverse effect on the safety of the operator of the truck.

\section{References}

[1] V. K. Bhagat, P. A. Wankhade, P. P. Gosh, "Development and structural analysis of translation carriage for reach truck," International Journal of Applied Research in Mechanical Engineering, 2(2), pp. 93-99, 2012.

[2] I. Doçi and V. Imeri, "Dynamic analysis of forklift during load lifting using modelling and simulations," International Journal of Current Engineering and Technology, 3(2), pp. 342-347, 2013.

[3] A. T. Meshram, "Finite element mast assembly of material handling equipment," International Journal of Technology, 3(1), pp. 50-55, 2013.

[4] S. B. Rane, H. Shirodkar, P. S. Reddy, "Finite element analysis and optimization of a forklift chassis," Altair Technology Conference, 1, pp. 1-6, 2013.

[5] K. Cline, "Failure of a high-capacity forklift fork," Microscopy Society of America, 10.S02, pp. 776-777, 2004.

[6] R. Miralbes, H. Malon, L. Castejon, "Design of accessories for the coupling in forklift trucks: Crane gibs and pallet box lock," Selected Proceedings from the 15th International Congress on Project Engineering, pp. 233-246, 2011.

[7] G. Stoychev and E. Chankov, "Investigation of dynamic stresses in a forklift truck lifting installation," Machine Design, pp. 75-80, 2009.

[8] G. Todorov, M. Ivanov, K. Kamberov, Sv. Stoev, "Design and virtual prototyping of a forklift transmission module," pp. 37-40, 2011. 